\title{
Role of Cultural Mapping within Local Development Processes: a Tool for the Integrated Enhancement of Rural Heritage
}

\author{
Vanessa Assumma ${ }^{1, a}$, Claudia Ventura ${ }^{2, b}$ \\ ${ }^{1}$ Via Tremulini Vico Perna $n^{\circ} 9,89124$, Reggio Calabria, Italy \\ ${ }^{1}$ Mediterranea University of Reggio Calabria - PAU - Department of Heritage, Architecture, Urban \\ Planning, Via Salita Melissari - 89124, Reggio di Calabria, Italy \\ aassumma.vanessa@gmail.com, bclaudia.ventura@hotmail.it
}

Keywords: Cultural Mapping, Local Development, Urban Regeneration, Rural Tourism, Tangible and Intangible Heritage, Community Driven Process.

\begin{abstract}
Cultural mapping consists in an innovative tool of knowledge, utilized in the local development processes to enhance territorial resources and to increase local growth in terms of environmental, social and economic sustainability. This research investigates links in strategic planning between heritage, communities and local identity, where knowledge analysis represents the starting-point to define a series of objectives, expressed by local community and by the whole society. Cultural mapping is here applied in the Grecanic Area, a Southern Italian region rich of material and immaterial resources in terms of history, nature, culture and it represents a possible instrument for local development, contributing to arise awareness of the local cultural heritage, discarded too many times just for an ephemeral seaside tourism. The research methodology is companied by a survey about the perceptions of the cultural values, material and immaterial, feeling by the community, tourists and visitors. Data are collected and elaborated as graphics and histograms to get an exhausting vision of the country, especially the historical traditions to the contemporary ones. The results are transferred in a Cultural planning's action within the borders of the Metropolitan city of Reggio Calabria.
\end{abstract}

\section{Introduction}

Since 90s Cultural mapping toolkit has become very popular in several downtowns of Europe, facing with contemporary issues like the difficult relationship between historic towns and periphery, whose effects are traduced in physical and social exclusion as well as marginality. Several strategic measures were adopted in cultural policy such as empowerment of social capital, creative environments and new governance models. Within a systematic view all these tools are named Cultural mapping. Still nowadays the relation between Cultural mapping and Cultural planning provides many positive effects through international and national applications.

This paper investigates and examines different international cases: the CMPP (Cultural Mapping Planning and Policy) in the Pacific context, focalizing the attention on Australian history and cultural landscape as perceived by aboriginal communities; the CCPF (Creative City Planning Framework) applied in Canada, where Cultural mapping and Cultural planning become one of three strategies to promote Canadian downtowns as Creative City. Italy is represented by M.U.S.I.C. project (Mediterranean Urban Sounds Interactive Culture) at CUCS of Turin 2013 [1], to promote the grew of Mediterranean community as Italy, Palestine, Egypt and Tunis, favoring the dialogue between community, stakeholders, public government and the culture as source of development of the entire Mediterranean. Therefore, promoting Cultural mapping in the Grecanic Area, is a secure step towards the sustainable development of rural areas in metropolitan peripheries. The Grecanic Area is situated in Reggio Calabria's Province and it is famous for an extraordinary tangible and intangible heritage, according to UNESCO's Convention on "Safeguarding of immaterial and Cultural Heritage" [2].

The research has developed a strategic survey, a versatile instrument for data collection, which is the questionnaire, based on the cultural values' perceptions expressed by local community, tourists 
and visitors of the Grecanic area (IT). The results are then transferred in the conclusive project, the Grecanic Ecomuseum, known as a pact with the community to take care of the territory.

\section{Theoretical background and challenges: new opportunities for Rural Areas}

Rural tourism is increasingly viewed as a panacea, raising the economic development of marginalized inner areas in Calabria Region (IT), stimulating social regeneration and improving the living conditions of rural communities. Less developed historic towns and valleys, afflicted by debilitating rural poverty and community migration towards the city's logistic poles, have considerable potential in attracting tourists in search of new, authentic experiences in areas of unexploited natural and cultural riches.

But several concepts in rural tourism need to be defined, such as the interrelation between sustainability, community and authenticity. Nowadays, promoting sustainability is surely a vital element in any planning process, because communities need to support themselves on the basis of available resources. So the conservation and preservation of cultural heritage becomes part of a holistic concept of place-based communities' sustainability, in which economic, social, cultural and political spheres must interfere to create enduring local development.

Furthermore the dependence of sustainability strategies upon local communities raises several questions about the nature and the functions of the community itself. Community participation in environmental decisions is putting pressure on planners to find new ways of fusing the expertise of scientists with insights from the local knowledge of communities. Using interviews, primary texts, and ethnographic fieldwork, reveals how the perception of territories is different and wide. But communities involvement into planning process, are important also because:

- local stakeholders actively participate in the protection and maintenance of cultural heritage;

- community residents are being recognized as an essential ingredient in the "hospitality atmosphere" of a tourism destination.

Over the last 30 years, interest in cultural planning has increased around the world. A number of handbooks and toolkits have been released in the US, Canada, the UK and Australia to support community leaders and policy makers to understand the relevance of cultural planning for local governments and to provide guidance for how to proceed in engaging in this process of cultural planning $[3,4,5,6,7,8]$. These handbooks describe, in different ways, a lengthy and complex cultural planning process. Despite various differences, they have some common procedural traits and goals. A common procedural trait is the layout of several steps to guide the process, and the common goals include the involvement of the community, the development of cultural resources and the solution of social issues. Cultural planning takes different forms in different countries and, despite the growing exchange of ideas, it has a variety of configurations. Main critical approaches to Cultural planning refer to this methodology as the planning of culture, so as a process of construction of places cultural identity and of manipulation of its integrity.

Indeed, Cultural planning can be seen as a strategic approach to cultural development, and the planning process is expressed by the expression of clear setting and goals, through the assessment of the existing situation, by identifying clear issues and priorities and finally implementing practical courses of action [7]. A culture-led planning might provide a fundamental framework able to guarantee sustainable and balanced uses of local resources, but mainly it can consistently contribute to the promotion of cultural diversity and to the protection of local authenticity.

Very often rural area are strongly affected by the tourism market pressure that force the development of this attractive form of tourism based on agriculture and landscape beauty. However the awareness of communities is still a week and not well deepen concept [9]. Moreover standard solutions are rarely compatible or successful in different contexts (see the Tuscan model explosion in rural tourism demand). The cultural identity of a community comprises who local people are and their backgrounds, tastes, tradition, rituals, experiences, diversity, talents and aspirations for the future. The cultural richness of a place is also governed by local heritage attributes and the natural and built qualities that attracted residents to the area and then tourists. Cultural planning demands recognition of the distinctive resources of a place in the first instance and then the development of 
policies and strategies rooted in those resources, with the main aim to guarantee the authenticity of territories nature. A pre-condition for identifying, harnessing and then exploiting creative potential of rural areas is to conduct a wide-ranging mapping (or audit) of possibilities based on exploring the distinctive assets of a place [10]. Such broad spectrum mapping of the local 'culture' can provide vital information to the policy-makers about the best way to respond more effectively to local needs while maximizing opportunities.

\section{The relation between Cultural mapping and local development processes in rural areas' international context: a comparative analysis}

The use of qualitative and quantitative data about the history and the culture perceived by the communities achieves an increased knowledge about the territory. The terms cultural and mapping create a valid tool to valorise the known and unknown in-situ resources, solving in the meantime problems and threats too many times ignored. The consideration of international and national applications is useful to verify the effects and the results generated by Cultural mapping. The examined case studies are: CMPP, known as Cultural Mapping, Planning and Policy Process, it is an instrument that involves many stakeholders of Pacific context, where community, governance, instruction, and religious groups joined to make an inventory, rich of knowledge, rituals, cultural place, because Culture is the richness of Pacific and everyone should have the chance to known it. Socially, CMPP involves women, guys, cultural groups, because are often marginalized.

Technically, the instrument considers several mapping techniques like GIS to research significant cultural place, the collection of qualitative and quantitative data and a list of cultural rituals, events and performances. So Culture is the starting-point for sustainable development as well as the cure for several forms of decay. CMPP is the first experiment of Cultural mapping in the Pacific area, thanks to Professor C. Mercer and Dr K. Teaiwa of Australian National University. They led a famous workshop on CMPP's approach and Cultural policy; the latter is a set of guide lines and directives for the regulation, management and localization of territorial resources and it should be received by agencies, stakeholders, governance, in order to be the engine of development and human progress in Oceania [11]. If local government doesn't accept community's aspirations, it will probably fail especially when society isn't actively involved in the planning process. A positive result is carried by Australia, where it can be found one of the oldest ethnic group of the world that resisted to European colonization: Aborigine culture. Cultural mapping focuses on the role cultural leaders, because of the great influence they engage among community and in Australia Queenie McKenzie fully represented this role in Texas Down Cattle Station, a very large wilderness area in East Kimberley region. Renamed The Law Woman she fought to save tangible and intangible heritage, assuring the correct transmission of cultural practices, values and ancient knowledge through songs, tales and ceremonies. The women of Warmun community wrote a book about her life and Aboriginal heritage: Written in the Land. The book had a great success: the sacred places and paths are mapped through cartography and aerial photos and the wildlife through photography. Many students are still now involved in a school project about Aborigine culture through some oral tale told by elders of Texas Downs, near ancient places, as Red Butte; later children can paint how seen and heard. The tales are told since several decades, without the need to write them and children are very interest toward their origins and sense of identity [12].

Another Cultural mapping's experience is CCPF (Creative City Planning Framework) developed by AuthentiCity [13] in five Canadian downtowns: Toronto, Vancouver, Calgary, Ottawa, Ville de Montreal. CCPF provides Cultural mapping influences highly cultural planning's action, because an increased knowledge is ineluctable to achieve important results in local development processes. So Cultural mapping, represents one of the three strategies of CCPF to launch downtowns as Creative cities, assuring a wide participation for the mobilization of resources [14]. The Hill Strategies Resources led an analysis about the artists inhabited in several districts of Canadian downtowns.

The census collects data about occupation in a period between $6^{\text {th }}$ May and $12^{\text {th }}$ May 2001 . The artistic occupations are organized in nine categories to demonstrate that 130700 artists express $0.8 \%$ of whole workforce in Canada. The investment for artistic skills improves the local economy and 
social well-being. There are mapped the most creative districts, especially the attractive ones for them, because of: economic apartments, access to work, opportunities as freelancer, access to the resources as galleries, performance spaces, associations, social networks and others. Organizations and/or policy makers to assure that programs and services are made correctly can use this analysis.

Microsoft MapPoint is the software used for the mapping elaboration of Canadian downtowns to highlight the most creative urban and rural districts. CCPF show that Arts, Culture and Heritage are the essential features for the future economy as heritage as well as quality of life. The measures propose the strengths for the improvement of cultural, economic and social resources: Cultural renaissance, Cultural diversity, attraction of new generations, Public Art, the figure of Museum as the future of history, Community art.

In Italy in 2013, the third Congress of the Italian University Network for Development Cooperation of Turin, promotes the M.U.S.I.C. project, which favors the cultural and economic growth starting from the dialogue between community, stakeholders and public administrations, through the mapping of traditional sounds, songs, and rhythms of Mediterranean Regions, like Italy, Palestine, Egypt and Tunis [1]. The analysis is led on common issues in cultural economy, such as: lack of cultural structures and activities financed by public administration, the indifference of investors in the cultural sector, the difficult dialogue between artists and cultural institutions and scarcity of community participation in heritage documentation. These questions cause an insufficient growth of cultural value's heritage and M.U.S.I.C. project want solve them through a common solution: the analysis of sounds to geo-locate users' contents in the web, extracting models of perceptions of urban and rural contemporary spaces, using a digital platform, finalized to the spatial regeneration of Mediterranean culture's heritage. So the knowledge of urban and rural systems will be more inclusive with stakeholders as well as with the cultural demand of citizens and consumers. Also the promotion of new professional figures in cultural economy, no-profit initiatives and educations to the sustainability could carry several positive results. The project shows a flexible and communicative structure because it is inspired to two important UNESCO's Conventions: The Convention on the Protection and Promotion of the Diversity of Cultural Expressions [15] and the Convention for the Safeguarding of Intangible Cultural Heritage [2,1].

M.U.S.I.C. project communicates also with several projects in Mediterranean context, such as Medina 2030, Athena, Doremihe and UNESCO chair; all these promote culture's heritage and ecosystems through the cooperation between Mediterranean Regions and Universities.

\section{Case study: the Grecanic Area (Italy), a land lost in time}

Cultural mapping recognizes the irreproducibility of heritage, according to the principle of preservation; in fact both ASEAN and UNESCO support Cultural mapping's intent because the preservation of the language, the traditions of ethnic minorities are the fulcrum of everyday life.

The individuation of the objectives, based on a series of comments, suggest and contacts coming from the community, favors the local identity and cooperation. Two types of interrogatives can help the research in small regional systems: What do we need to know?, Who needs to know?[16].

Culture and local identity is the key for a sustainable local development. Cultural mapping could give important results in the Grecanic Area. This is one of the most famous areas in Calabria for the naturalistic and cultural heritage, preserved nowadays in critic conditions, risking the disappearance. The Grecanic Area is situated in the Province of Reggio Calabria and comprehends the municipalities of Melito Porto Salvo, Bagaladi, Cardeto, Roghudi, Roccaforte del Greco, Africo, part of Condofuri, Bova, Staiti and Brancaleone, but the administrative ambit doesn't coincide with the cultural one: the territorial context should result more high than the given borders. According to the philologist G. Rohlfs [17], the Grecanic Area in fact extended from Southern Ionian side to Catanzaro's Isthmus until the Modern Age, but the historical and religious dynamics caused the migration of Grecanic community. The radical transformations have been in the last fifty years: donkeys and mule tracks were replaced with cars and driveways, such as Provincial roads, which represent nowadays the only communication road with the coast, and the depopulation of historic towns caused the carelessness toward Nature and Culture's resources. Although the worrying 
scenery, the Grecanic Culture survived marginally for centuries, maintaining the oldest rural traditions, as the Grecanic language, that is still the most important vehicle of Immaterial Culture's transmission [18]. But the relationship between Man and Nature isn't the same again, because of hydrogeological phenomena that damaged the historic towns and primary services. In last decades the economy is hardly influenced by summer season, where the seaside tourism caused several environmental impacts, failing to recall the innate vocation of Grecanic area. Little business realities were born to support the sustainable tourism in the area, such as agritourism, cultural organizations and rural tourism services, with the intent of diversifying the touristic offer through the material and immaterial cultural resources enhancement. The main aim of the research is to investigate the opportunity to create an Ecomuseum to enhance the cultural heritage of the case study. The project hypothesis is based on the vision of a Grecanic Ecomuseum as pact with the community to take care of own territory [19]. Taking care means to enhance naturalistic and cultural resources for present and future generation. Therefore the Grecanic Ecomuseum could reflect the innate vocation of the area, starting from the ancient relationship between seaside and mountains, signed by fluvial axes, historic towns and peculiar crops. This charming scenery is contrasted by the sprawling of industries and precarious Provincial roads. As well as cultural and natural resources, the infrastructural network should be enhanced for its transversal role: the infrastructural problems often caused the less of communication with the inner towns, passing on Culture, Nature, Economy and Society. Moreover the creation of a Grecanic Ecomuseum can surely provide a series of sustainable paths to link the coast and the mountains in accordance with the sustainable rural tourism principles. The Water-paths comprehends the fluvial axes of Amendolea's Valley because many of them are formally recognized as SIC areas in cartography but in the reality they turned into illegal dump damaging cultivations, animals, society and increasing the hydrogeological risk. The Everyday life's path links the inner towns for commercial and religious reasons as in the past; the Bicycle's path and other touristic services allow a diversified and sustainable offer and then an environmental and technological park in the heart of National Park of Aspromonte. The figure of Ecomuseum reflects the territory itself, a structure without wall and container of cultural and natural resources, where people could better appreciate their own heritage and the sense of belonging to the territory, transmitting to the new generation the importance of a both sustainable present and future.

At the study starting, a first survey was helpful to reveal how local communities perceive the cultural and natural resources. The research tool used during the survey phase is the assisted questionnaire that was conducted from $20^{\text {th }}$ November to $29^{\text {th }}$ November 2013 in the municipalities of Bova, Palizzi and Reggio Calabria and that involved a sample of residents, tourists and visitors between 18 and over 65 years old. The questionnaire introduces the survey's aims, which are the classification of the community's sample in terms of age, gender, job, residence, date of compilation and then a set of open and closed questions. In accordance to the Funnel Technique [20], the questionnaire starts from easier questions about visual and affective perceptions, until to specific ones focalizing on material and immaterial resources, services and quality of life. Last questions regard how the community perceived the planning of a potential Grecanic Ecomuseum and the grade of information about the contemporary and sustainable typologies of museums. The questions set are both quantitative and qualitative following the Linkert Scale [21], expressing a quantitative accord or disaccord in a scale from 1 to 5 points, as well as a qualitative accord or disaccord from "Nothing" to "A lot"; the questions also provides a free section to write some opinion, suggest and a box for the refrain's faculty. The questionnaire's results are elaborated in Microsoft Excel through histograms and percentages (Tab.1,2). Two points of view emerged from data analysis: the community's view and the tourists' perspective. The community's point of view underlines the links between affective perceptions and the visual ones, such as the homeland and the relative landscape. Old stories and religious traditions about the Grecanic area, emerged during this study step, like S.Sebastiano and S.Leo cult, and some rural tales like "The goat and cricket's tale" and "The Legend of Pentedattilo". Many respondents have shown great attention about the sectors that should be developed in the context. The community perceives the Grecanic Ecomuseum as 
"sharing of places and traditions", showing a positive opinion from "Rather" to "A lot". Many tourists and visitors don't known yet the Grecanic area's heritage because most of them take just a seaside holiday break in summer. Therefore they don't know tales, traditions, naturalistic and cultural resource which should be valorised. Who really visits the Grecanic Area is mostly motivated by cultural events, such as "Paleariza", an ethnic music festival that allows the knowledge of historical, cultural, naturalistic and contemporary features of the place. Few respondents suggested the historic oil mills as part of the heritage which can be valorised in historic and economic terms; the olive oils could be produced for alimentary and aesthetic market. Tourists and visitors define the Grecanic Area as ancient or landscape, but in the meantime a bit functional, which represents a weakness graving on mobility and economy's sector. The opportunity of having a Grecanic Ecomuseum is perceived as "travelling through the history of a place" in a grade of accord or disaccord from "Much" to "A lot"[22].

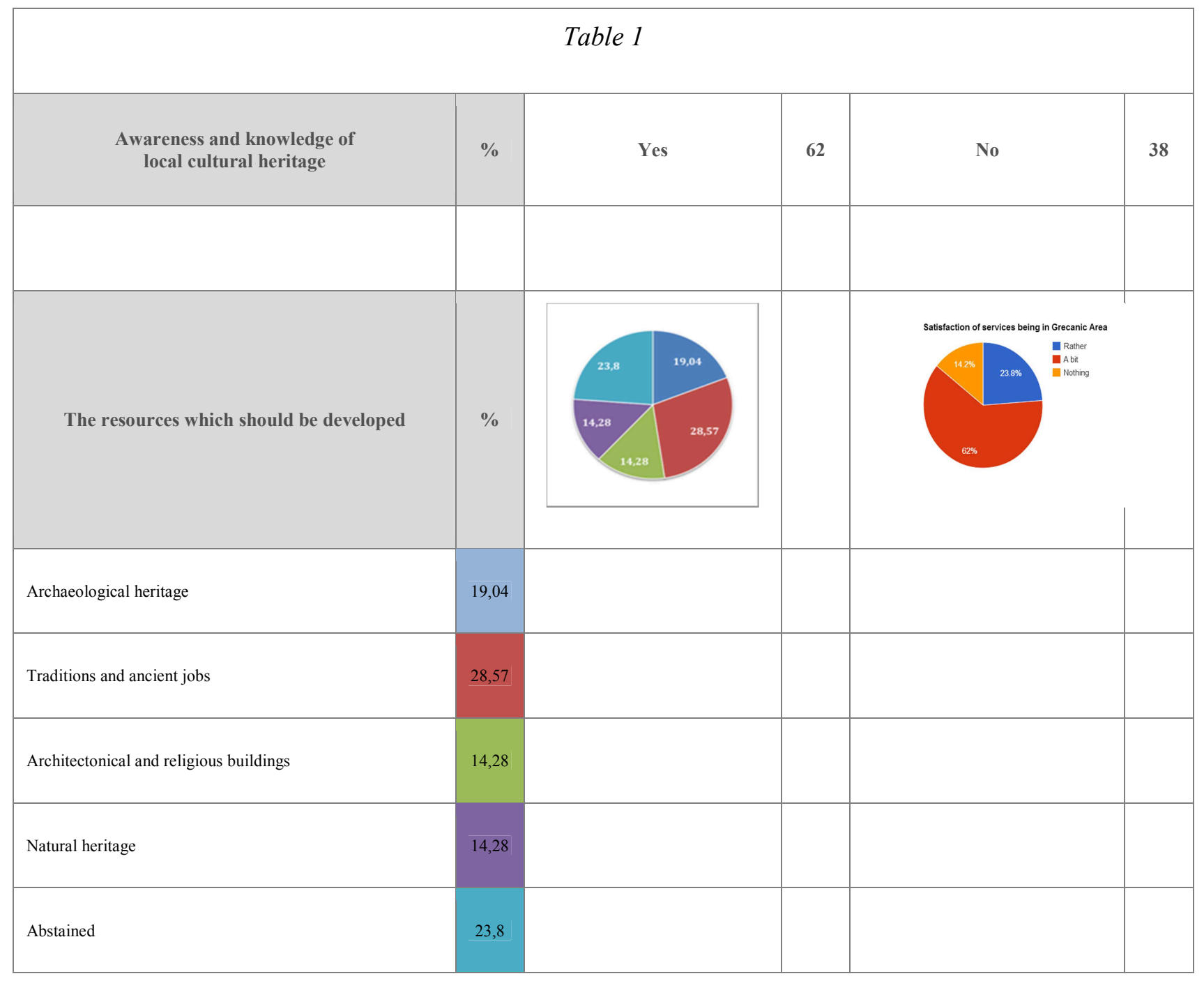




\begin{tabular}{|l|l|l|l|l|}
\hline \multicolumn{2}{|c|}{ Table 2 } \\
\hline $\begin{array}{c}\text { The immaterial resources known by residents, } \\
\text { tourists and visitors }\end{array}$ & $\%$ & & & \\
\hline Folktales & & & & \\
\hline Legends & 23,07 & & \\
\hline Ancient knowledge & 07,70 & & \\
\hline Dance and folk songs & & & \\
\hline
\end{tabular}

\section{Conclusions}

At the base of the concept and of best practices of cultural planning lays the idea that policies in favor of communities must be interpret as integrated policies for local development. Surely cultural planning, as link between cultural resources and planning, is also a strategy to expand the view of those involved in planning, encouraging cooperation between the strictly urban and territorial planning, primarily looking to the physical space and to intangible cultural elements.

Cultural planning is spreading to all corners of the globe, and the study of cultural tourism phenomenon with it. This surely has begun to create awareness of different regional and sustainable styles of cultural tourism. Innovative or alternative management strategies are the core basis for a new vision development: for example ecomuseums introduce, manage, and preserve the cultural and natural heritage of the local communities. It is considered as a new and specialized field of study in ecotourism and is believed to lead to sustainable development in tourist industry, while preserving natural, cultural, and spiritual heritage and the rural contexts. This dimension of cultural planning establishes a link between cultural resources and the different types of public policies, aiming to transform the concepts and basic assumptions upon which they are based and, therefore, the process of formulation and implementation of these policies through the involvement of local communities, including through cultural mapping. A rural ecomuseum could be a natural and dynamic site, representing the unique and precious identity of a rural area. It is a new means of traditional culture protection and it also has demonstrative effect on the tourist development of the ethnic cultural landscape.

\section{Acknowledgements}

Part of this work has been presented in the Integrated Course of "Regional Economy" 2012/2013, taught by Prof.ssa L. Della Spina of Dept. PAU, University Mediterranea of Reggio Calabria. 


\section{References}

[1] A. Contin, P. Bellaviti, A. Frigerio: M.U.S.I.C. Mediterranean Urban Sounds Interactive Culture, Imagining cultures of cooperation: universities networking to face the new development challenges, Department of Architecture and Urban Studies, Politecnico of Milano CUCS Torino (2013)

[2] UNESCO: Convention on Safeguarding of Intangible Cultural Heritage, Paris (2003)

[3] G. Baeker: Rediscovering the wealth of places: A municipal planning handbook for Canadian communities, Municipal World, St. Thomas, Ontario (2010)

[4] T. Borrup: The creative community builder's handbook: How to transform communities using local assets, arts, and culture, Fieldstone Alliance, Saint Paul, MN (2006)

[5] C. Dreeszen: Community cultural planning handbook: A guide for community leaders, Americans of the Arts, Washington DC (1997)

[6] D. Grogan, C. Mercer: The cultural planning handbook, Allen \& Unwin, St. Leonards (1995)

[7] M. Guppy: Better places, richer communities: Cultural Planning and local development $-a$ practical guide, Australia Council for the Arts, Sidney (1997)

[8] A. Russo, D. Butler: Cultural planning toolkit, Legacies Now and Creative City Network of Canada, British Columbia (1991)

[9] G. Cassalia, C. Ventura: Cultural landscape preservation as key factor for rural tourism, in: Conference Proceedings Tourism and the Shifting Values of Cultural Heritage, Visiting Pasts, Developing Futures, International Conference, Taipei, Taiwan (2013)

[10] C. Ventura: Vision or Invasion? Immagine, immaginazione e promozione nella tutela del patrimonio culturale, in: A. Bianco (ed.), Articolo 9, Aracne, Roma (2013)

[11] C. Mercer, K. Teaiwa: Cultural Mapping, Planning and Policy Toolkit, Secretariat of the Pacific Community, Noumea (2011)

[12] J. J. Field, Q. McKenzie: Written in the land: The life of Queenie McKenzie, Melbourne Books, Melbourne (2008)

[13] AuthentiCity: Creative city planning framework, City of Toronto, Toronto (2008)

[14] R. Davies: A Map of Toronto's Cultural Facilities, Division of Economic Development, Culture and Tourism, Toronto (2011)

[15] UNESCO: Convention on the Protection and Promotion of the Diversity of Cultural Expressions, Paris (2005)

[16] Arts now, Cultural mapping toolkit, A Partnership between 2010 Legacies Now \& Creative City Network of Canada, Canada (2010)

[17] G. Rohlfs, P. Martino: L'isola grecanica dell'Aspromonte. Aspetti sociolinguistici in: Atti dell'XI Congresso internazionale SLI, vol 16/1, Bulzoni, Roma, (1980), pp. 305-341

[18] E. Castagna: Pucambù, Guida per il turismo sostenibile nell'Area Grecanica, Calabria letteraria, Reggio Calabria (2002)

[19] M. Maggi: Ecomusei. Guida Europea, Allemandi, Torino (2002)

[20]C. Marshall, G. B. Rossman: Designing qualitative research, Sage Publications, Thousand Oaks, California (1999)

[21] H. R. Bernard: Social research methods: Qualitative and quantitative approaches, Sage Publications, Thousand Oaks, California (2000)

[22] V. Assumma: La valorizzazione del patrimonio culturale rurale attraverso il Cultural Planning: il ruolo del Cultural Mapping nei processi di sviluppo locale, Reggio Calabria (2013) 